\title{
Evaluation of Surface Roughness of a Ni-Cr Alloy Treated With the Nd/YAG Laser and the Sandblast Technique
}

\author{
Elnaz Moslehifard ${ }^{1}{ }^{\circledR}$ Mir Mahdi Seyyedashrafi ${ }^{\circledR}$, Nasim Khosronejad ${ }^{3^{*}}$ \\ 'Department of Prosthodontics, Faculty of Dentistry, Tabriz University of Medical Sciences, Tabriz, Iran \\ ${ }^{2}$ Department of Oral and Maxillofacial surgery, Urmia University of Medical Sciences. Urmia, Iran \\ ${ }^{3}$ Department of Prosthodontics, Faculty of Dentistry, Urmia University of Medical Sciences. Urmia, Iran
}

\author{
*Correspondence to \\ Nasim Khosronejad, \\ Faculty of Dentistry, Urmia \\ University of Medical Sciences, \\ Urmia, Iran. \\ Tel: +989124390427, \\ Email: khosronejad_1986@ \\ yahoo.com
}

Received: August 9, 2020 Accepted: June 11, 2021 Published online November 6 , 2021

\section{Introduction}

Porcelain-fused-to-metal fixed dental prostheses with combined metallic strength and the esthetic features of porcelain have been used in dentistry for years. They are still considered as an excellent choice for treating the patients ${ }^{1}$ thanks to their low cost and simple cementation technique compared with metal-free restorations, as well as reproducing the lost dentition naturally in most of the restorative treatments. ${ }^{2}$ Selection of the proper dental alloys and their treatment to obtain a desirable metalceramic bond is considered one of the major factors of the success of these restorations. ${ }^{3}$ As noble metal casting alloys are biocompatible, they are suggested for the fabrication of metal substructure of metal-ceramic restorations. Also, these alloys act mechanically well and establish an excellent bond with dental ceramics. However, considering the costs of precious alloys and recent advances in ceramic technology, base metal casting alloys, for example cobalt-chromium and nickel-chromium (NiCr), are substituted. ${ }^{4}$ Nowadays, base metal alloys are mainly used to fabricate fixed metal-ceramic restorations. ${ }^{1}$ Their mechanical properties make it possible to fabricate the restorations with lower thickness and satisfactory hardness. Difficulties in handling, potential biological risks, as well as forming uncontrolled chromium oxide in specific alloys are considered as major disadvantages. ${ }^{5}$ The thermal expansion coefficients of dental porcelain and Ni-Cr dental alloy are similar. The casting technique is utilized to make the metal substrate ready for economic considerations. In spite of the difficulties for the casting of $\mathrm{Ni}-\mathrm{Cr}$ dental alloy, it is preferred due to its potential for oxidation during casting and high melting range. ${ }^{6}$ The success of the metal-ceramic restorations mainly relies on the formation of a stable adhesive layer between these two materials. The mechanism of metal-ceramic bond is not yet completely clear but the results of previous studies 
show that it can be the outcome of the metal alloy proper oxidation added to the interdiffusion of ions between the metal and ceramic substrate. ${ }^{5}$ The metal-ceramic restorations consist of a metal substructure which is mechanically and chemically bonded to a ceramic veneer. The chemical bond is achieved through baking at elevated temperatures. Having a metal substructure may lead to failures which can occur at the metalporcelain interface. Chemical bonding, micromechanical retention and Van der Waals forces have been observed for porcelain bonded to metal as the major effect of a union. Chemical bonding is characterized by the direct transfer of electrons between the oxygen in the vitreous part of the ceramic and the oxidation of the metal. To increase the metal-ceramic bond strength by means of increasing the metal wettability by porcelain and limiting the oxide layer formation as thin as possible, some surface treatments have been evaluated. The main treatments are using bonding agents, degasification, preoxiding the metal before using porcelain, air-abrasion, heat treatment, laser irradiation ${ }^{1,7-9}$ and mechanical retention with carbide burs and diamond mounted tips. ${ }^{2}$ It has not been yet completely clear what the mechanism of the metal-ceramic bond is. The adhesive mechanism between the metal and ceramic has not been completely defined yet. However, some studies have indicated the suitable oxidation of the metal alloy. Furthermore, the strongest metal-ceramic bond has been achieved by means of airabrasion in nickel-chromium alloys. ${ }^{5}$ The integration of laser and sandblasting surface treatments indicated rougher surfaces than the case when sandblasting is done separately, especially for metal specimens. ${ }^{1}$ In fact, this combination makes the surfaces of zirconia ceramics rougher as compared to sandblasted technique or Nd:YAG laser irradiation. ${ }^{9}$ In addition, femtosecond laser treatment was more effective in zirconia surface roughening. ${ }^{8}$ Given all of the aforementioned methods for enhancing bond strength between metal and porcelain, laser etching is considered as a surface treatment which can control micro-topography due to its deep penetration relying on the material irradiated, leading to more surface roughness and stable surface morphology. ${ }^{10}$

Therefore, as Nd:YAG laser treatment developed an effective bond of porcelain to titanium, ${ }^{11}$ the present study was planned to evaluate the impact of various parameters of Nd:YAG laser etching on nickel-chromium alloy surface roughness as compared with air-abrasion.

\section{Materials and Methods}

96 disk-shaped molds (2-mm thickness and 5-mm diameter) in total were made of Duralay resin.

First, the patterns of Duralay resin were produced using phosphate bonded investment in casting rings. Then, the specimens were cast in a vacuum by utilizing a casting machine under a vacuum pressure of $580 \mathrm{~mm}$ $\mathrm{Hg}$ at $1340^{\circ} \mathrm{C}$. The Ni-Cr casting alloy (Thermabond Alloy Supercast, MFG, Los Angeles, CA, USA) (Supercast casting alloy: $75 \%$ nickel, $15 \%$ chromium and $5 \%$ molybdenum) was cast through using a casting machine and a gas-oxygen torch. In addition, the casting ring was plunged under running cold water to disintegrate the investment when the red glow at the bottom disappeared. The investment residual was eliminated through a toothbrush, and any remaining traces were ultrasonically eliminated. Castings were pickled in $50 \% \mathrm{HCl}$ in order to eliminate the metallic oxides. Then, the metal excess was eliminated by carbide discs and bars. In addition, the specimen sizes were standardized with a digital caliper with the accuracy of \pm 0.1 millimeter (Digital Caliper, Guanglu, Strikhlu, Germany), and the required revisions were made by a diamond bur.

The surfaces of 16 disc-shaped specimens were airabraded using $50 \mu \mathrm{m}$ alumina particles under a pressure of 3-4 bar and $10 \mathrm{~mm}$ distance for 10 seconds. ${ }^{5,12}$ The rest of the surface-treated specimens were divided into five groups with Nd:YAG laser (Pulse width: 0.2-1 ms, energy density: $(4.30-7) \times 10$ (6), wavelength: $1064 \mathrm{~nm})$ irradiation by a glass fiber with a linear movement and in a direction perpendicular to the surface (Neolaser L, Girrbach Dental Systems, Pforzheim, Germany). Table 1 shows the factors of the laser applied.

The surface roughness of each disk-shaped specimen (sandblasted or laser etched) was measured in 3 points by a profilometer (Mahr M 300 C, Germany) and the average roughness $(\mathrm{Ra})$ values were calculated. This measurement was made for all the 96 specimens, and the Ra values were collected. The surface roughness values were analyzed using the $t$ test and one-way ANOVA.

\section{Results}

Kolmogorov-Smirnov test results indicated the normal distribution of the data. Surface roughness measurements were performed on 3 random locations on the specimens to calculate the average values. Table 2 shows the mean $\mathrm{Ra}$ and standard deviations.

Table 1. The output parameters of laser-treated groups

\begin{tabular}{|c|c|c|c|c|c|}
\hline & Group A & Group B & Group C & Group D & Group E \\
\hline Energy $(\mathrm{m})$ & 122 & 122 & 122 & 102 & 102 \\
\hline Spot size & 1.5 & 3.5 & 3.5 & 3 & 3 \\
\hline Frequency $(\mathrm{Hz})$ & 20 & 20 & 10 & 10 & 20 \\
\hline Irradiation duration (s) & 20 & 20 & 20 & 20 & 20 \\
\hline
\end{tabular}


Table 2. Mean and standard deviation of surface roughness (Ra)

\begin{tabular}{lccc}
\hline Group & Mean & Standard deviation & N \\
\hline Laser (A) & 1.196 & 0.067 & 16 \\
Laser (B) & 1.732 & 0.274 & 16 \\
Laser (C) & 1.906 & 0.229 & 16 \\
Laser (D) & 1.554 & 0.119 & 16 \\
Laser (E) & 1.594 & 0.226 & 16 \\
Sandblast & 1.979 & 0.183 & 16 \\
\hline
\end{tabular}

The Ra data were analyzed by the pairwise $t$ test. Based on the results, a significant difference was observed in the surface roughness of the specimens in terms of the surface treatment type $(P<0.01)$. The surface roughness of the sandblasted group was higher than that of the laseretched groups. The results of one-way ANOVA indicated a significant difference between the Ra values of the laseretched groups $(P<0.05)$ (Figure 1$)$. Among the laseretched groups, group $\mathrm{C}$ had the highest surface roughness, which was laser-irradiated with $122 \mathrm{~mJ}$ energy, $10 \mathrm{~Hz}$ frequency, $3.5 \mathrm{~mm}$ spot size, and 20-second irradiation duration. Group A had the lowest surface roughness, which was laser-irradiated with $122 \mathrm{~mJ}$ energy, $20 \mathrm{~Hz}$ frequency, $1.5 \mathrm{~mm}$ spot size, and 20 -second irradiation duration. The results of the LSD test used to analyze the pairwise comparison of the laser-etched groups showed that the surface roughness of laser-treated specimens of

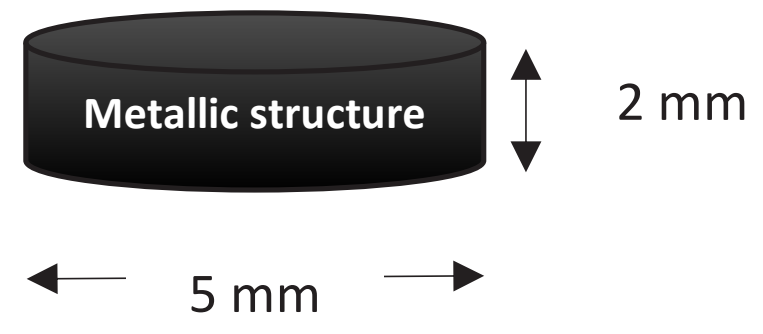

Figure1.The shape of specimens groups $\mathrm{B}$ and $\mathrm{E}$ as well as groups $\mathrm{D}$ and $\mathrm{E}$ were similar (Figure 2). However, the surface roughness of the other groups of the specimens was different.

Based on the results, the surface roughness of the sandblasted group was higher than that of the laseretched groups.

\section{Discussion}

Developing a lasting bond of the ceramic to metal alloy is considered the main factor for a successful restorative treatment. The growing body of research on the nature of the metal-ceramic bond has resulted in identifying chemical union, micro-mechanical retention and Van der Waals forces as the main determinants. ${ }^{2}$

In order to produce sufficient roughness of the surface with a high purity degree compared to other surface treatment methods, laser processing of the implant surface is considered as a new method of surface treating. ${ }^{4,13}$ Cho and Jung ${ }^{14}$ reported that laser etching is an effective method of creating a sufficiently roughened titanium surface. Wagner ${ }^{15}$ indicated that electron-beam thermal treatment and laser irradiation can be utilized to modify the microstructure of titanium surfaces with no contamination, which can optimize the surface roughness.

The energy level of laser irradiation determines the amount of metal superficial changes. Converting light energy into heat is considered as the main process which takes place in treating by laser, and the most important interaction is absorbing the heat by the substrate laser treated. ${ }^{16,17}$

Kara et $\mathrm{al}^{12}$ evaluated the impact of $\mathrm{Nd}$ :YAG laser irradiation compared with acid etching with $5 \% \mathrm{HF}$ and air-abrasion with alumina particles on roughness and bond strength as three surface treatments in low-fusing ceramics in order to obtain the best bond of resin cement to ceramic restorations, and they reported that airabrasion is the most effective method of surface treatment for enhancing the bond strength.

Kim et $\mathrm{al}^{11}$ compared the shear bond strength of the ceramic to titanium created by Nd:YAG laser treatment

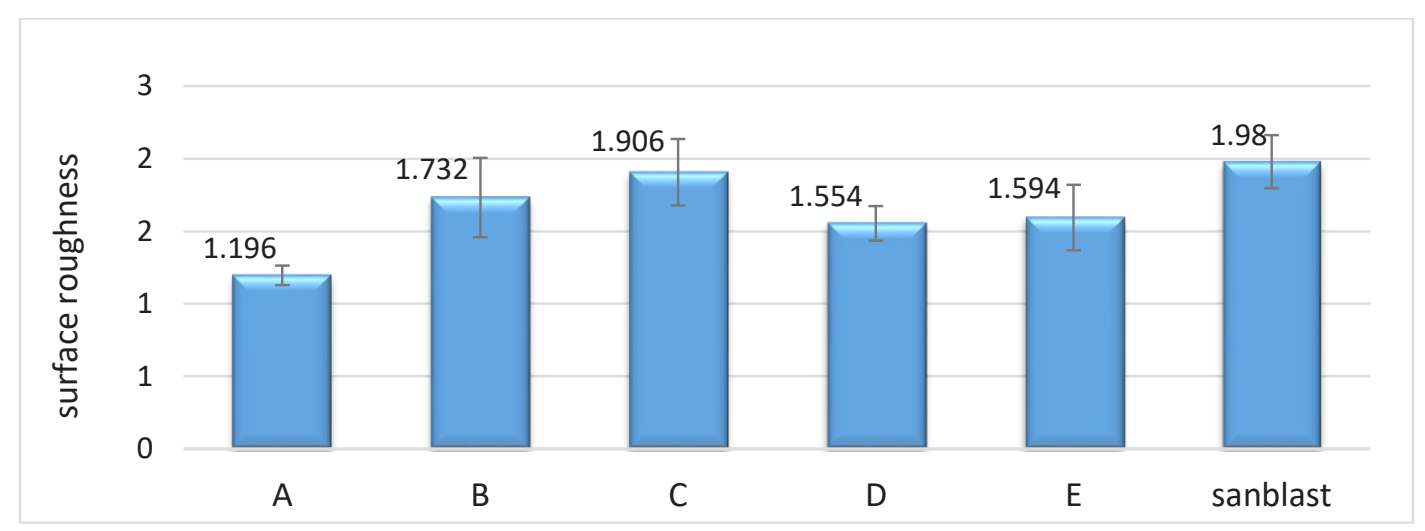

Figure 2. Average surface roughness 
with airborne particle abrasion, acid etching with 10\% $\mathrm{HCl}$ and machining. They concluded that laser-etching of titanium surfaces by using an Nd:YAG laser is more effective than other methods in increasing the bond strength of porcelain to titanium.

Kirmali et al assessed the surface roughness created by six different surface treatment methods on 120 IPS e-max ZirCAD pre-sintered zirconia blocks. The changes in the morphological characteristics of $\mathrm{ZrO} 2$ were analyzed by scanning electron microscopy (SEM). Sandblasting, sandblasting + Nd:YAG laser treatment, Er:YAG laser treatment and sandblasting + Er:YAG laser irradiation made the surfaces rougher than other surface treatments. Based on the results, using the Nd:YAG laser in the zirconia surface separately is not effective in changing the morphology. ${ }^{9}$

Kara et al. assessed the impact of different laser systems (femtosecond (FS), Nd:YAG (NY), and Er:YAG (EY) lasers) on shear bond strength of zirconia ceramic discs and their surface roughness. No difference was observed between the two zircon ceramics and an effective surface treatment was produced by the femtosecond laser. ${ }^{8}$

Sayin Ozel et al used various surface treatments (sandblasting, sandblasting $+\mathrm{Nd}$ :YAG laser, and sandblasting + Er:YAG laser) on disk-shaped specimens in resin cement bonded to yttria-stabilized tetragonal zirconia (Y-TZP) ceramic and bonded to $\mathrm{Ni}-\mathrm{Cr}$ base metal alloy. They evaluated the shear bond strength and surface roughness $(\mathrm{Ra})$ related to them. Based on the results, the sandblasting surface and combined laser treatments resulted in creating rougher surfaces compared to the case when sandblasting was done separately. Finally, higher shear bond strength of resin cement was observed when sandblasting was performed alone compared to the combined laser and sandblasting treatment in both metal and zirconia. ${ }^{1}$

Regarding the results of the previous study, ${ }^{2}$ no appropriate test is available to evaluate the metal-ceramic bond strength. However, the shear test is considered the most appropriate test for measuring the metal-ceramic bond strength. ${ }^{11}$

A common nickel-chromium alloy was implemented in our study that showed excellent marginal integrity without any adverse reaction. This alloy has desirable mechanical characteristics such as hardness, tensile strength, and elasticity. ${ }^{18}$ Airborne-particle abrasion in the control group and Nd:YAG laser (Wavelength: $1064 \mathrm{~nm}$, pulse width: $0.2-1 \mathrm{~ms}$, energy density: $(4.30-7) \times 10(6)^{19,20}$ treatment with different characteristics were utilized to treat the surfaces.

The $\mathrm{Ra}$ parameter indicates the total roughness of a surface defined as the arithmetical mean of all absolute distances related to the roughness profile from the centre line based on the measured length. Surface roughness is considered as the finer irregularities of the surface texture, which results from the production process or material condition.

The highest $\mathrm{Ra}$ value was reported in sandblasted specimens $(1.979 \pm 0.183 \mu \mathrm{m})$ and was significantly higher than laser-treated groups. Among the laser-treated groups, the highest and lowest $\mathrm{Ra}$ values were recorded in group $\mathrm{C}(1.906 \pm 0.229 \mu \mathrm{m})$ and group $\mathrm{D}(1.554 \pm 0.119$ $\mu \mathrm{m})$, respectively. $\mathrm{Ra}$ increased in the present study when the energy, spot size, and frequency of laser irradiation increased. Further, the SEM analysis showed that sandblasting increased surface roughness of $\mathrm{Ni}$ $\mathrm{Cr}$ alloy more than laser etching. Laser-treated surfaces were smoother compared to the specimens sandblasted. According to the results, sandblasting cannot be replaced by laser treatment yet, but more investigations may lead to making the laser treatment a standard method of surface treatment.

It seems that there is a correlation between the surface roughness of the metal and its porcelain bond strength in porcelain fused to metal (PFM) restorations. So, increasing the surface roughness can prolong the restoration durability. A proper technique and sufficient information about pre-treatment techniques are required to reach successful long-term bonding. The highest bond strength was obtained by selecting a suitable bonding system and a standardizing technique related to the surface treatment.

Further research should be conducted on the shear bond strength and surface roughness of Nd:YAG laser-treated surfaces with different properties in order to increase values as well as sandblasted specimens. Furthermore, future studies can focus on the relationship between surface roughness and shear bond strength.

\section{Conclusion}

Regardless of the limitations in the current study, the sandblasted specimens showed the highest surface roughness values. The surface roughness of the lasertreated groups was significantly different depending on the properties of the applied laser. Therefore, airborne particle abrasion made the alloy surface rougher than laser treatment.

\section{Ethical Considerations}

This study was approved by the research ethics committee of the Tabriz University of Medical Sciences.

\section{Conflict of Interests}

The authors declare that they have no conflict of interest.

\section{Acknowledgements}

The present study was conducted based on a dataset from an MSc thesis entitled "Comparison of the effect of Nd:YAG laser and sandblast on surface roughness of a commercial $\mathrm{Ni}-\mathrm{Cr}$ alloy and its porcelain shear bond strength" registered at Tabriz University of Medical Sciences, Faculty of Dentistry (reference number 
198/T). The thesis was supported by the Vice-Chancellor for Research at Tabriz University of Medical Sciences (Iran).

\section{References}

1. Sayin Ozel G, Okutan Y, Oguz Ahmet BS, Ozdere E. Effect of Combined Surface Treatments on Surface Roughness and Resin Bond Strength to Y-TZP Ceramic and Nickel-Chromium Metal Alloy. Photomed Laser Surg. 2019;37(7):442-450. doi:10.1089/photob.2018.4590.

2. Lombardo GH, Nishioka RS, Souza RO, Michida SM, Kojima AN, Mesquita AM, et al. Influence of surface treatment on the shear bond strength of ceramics fused to cobalt-chromium. J prosthodont. 2010;19(2):103-111. doi: 10.1111/j.1532-849X.2009.00546.x

3. Dimitriadis K, Spyropoulos K, Papadopoulos T. Metalceramic bond strength between a feldspathic porcelain and a Co-Cr alloy fabricated with Direct Metal Laser Sintering technique. J Adv Prosthodont. 2018;10(1):25-31. doi: 10.4047/jap.2018.10.1.25

4. Akova T, Ucar Y, Tukay A, Balkaya MC, Brantley WA. Comparison of the bond strength of laser-sintered and cast base metal dental alloys to porcelain. Dent Mater. 2008;24(10):1400-1404. doi: 10.1016/j.dental.2008.03.001

5. do Nascimento C, Miani PK, Bezzon OL, Goncalves $M$, de Albuquerque Junior RF. Shear bond strength between $\mathrm{Ni}-\mathrm{Cr}$ alloy bonded to a ceramic substrate. Gerodontology. 2012;29(2):e909-913. doi: 10.1111/j.17412358.2011.00585.x

6. Liu Y, Wang Z, Gao B, Zhao X, Lin X, Wu J. Evaluation of mechanical properties and porcelain bonded strength of nickel-chromium dental alloy fabricated by laser rapid forming. Lasers Med Sci. 2010;25(6):799-804. doi: 10.1007/ s10103-009-0690-3

7. Kunt GE, Guler AU, Ceylan G, Duran I, Ozkan P, Kirtiloglu T. Effects of Er:YAG laser treatments on surface roughness of base metal alloys. Lasers Med Sci. 2012;27(1):47-51. doi: 10.1007/s10103-010-0844-3

8. Kara O, Kara HB, Tobi ES, Ozturk AN, Kilic HS. Effect of various lasers on the bond strength of two zirconia ceramics. Photomed Laser Surg. 2015;33(2):69-76. doi: 10.1089/pho.2014.3841

9. Kirmali O, Akin H, Kapdan A. Evaluation of the surface roughness of zirconia ceramics after different surface treatments. Acta Odontol Scand. 2014;72(6):432-439. doi: $10.3109 / 00016357.2013 .853320$

10. George R, Walsh LJ. Performance assessment of novel side firing flexible optical fibers for dental applications. Lasers Surg Med. 2009; 41(3):214-21. doi: 10.1002/lsm.20747.

11. Kim JT, Cho SA. The effects of laser etching on shear bond strength at the titanium ceramic interface. J Prosthet Dent. 2009;101(2):101-106. doi: 10.1016/S0022-3913(09)60002-0

12. Kara HB, Ozturk AN, Aykent F, Koc O, Ozturk B. The effect of different surface treatments on roughness and bond strength in low fusing ceramics. Lasers Med Sci. 2011;26(5):599-604. doi: 10.1007/s10103-010-0806-9

13. Gaggl A, Schultes G, Muller WD, Karcher H. Scanning electron microscopical analysis of laser-treated titanium implant surfaces--a comparative study. Biomaterials. 2000;21(10):1067-1073. doi: 10.1016/s01429612(00)00002-8

14. Cho SA, Jung SK. A removal torque of the lasertreated titanium implants in rabbit tibia. Biomaterials. 2003;24(26):4859-4863. doi: 10.1016/s01429612(03)00377-6

15. Wagner WC. A brief introduction to advanced surface modification technologies. J Oral Implantol. 1992;18(3):231-235.

16. van As G. Erbium lasers in dentistry. Dent Clin North Am. 2004;48(4):1017-1059, viii. doi: 10.1016/j.cden.2004.06.001

17. Coluzzi DJ. Fundamentals of dental lasers: science and instruments. Dent Clin North Am. 2004;48(4):751-770. doi: 10.1016/j.cden.2004.05.003

18. Inoue $\mathrm{K}$, Murakami $\mathrm{T}$, Terada $\mathrm{Y}$. The bond strength of porcelain to Ni-Cr alloy--the influence of tin or chromium plating. Int J Prosthodont. 1992;5(3):262-268.

19. Lusquinos F, De Carlos A, Pou J, Arias JL, Boutinguiza M, León B, et al. Calcium phosphate coatings obtained by Nd:YAG laser cladding: physicochemical and biologic properties. J Biomed Mater Res A. 2003;64(4):630-637. doi: 10.1002/jbm.a. 10440

20. Moslehifard E, Khosronejad N, Fahimipour F. Comparison of the Effect of Nd:YAG Laser and Sandblasting on Shear Bond Strength of a Commercial Ni-Cr Alloy to Porcelain. J Dent Mater Tech. 2016;5(3):114-119. doi: 10.22038/ JMDT.2016.6994 